\title{
A METHOD FOR DETERMINATION AND STANDARDIZATION OF PERFORMANCE PARAMETERS FOR AIRCRAFTS WITH ELECTRIC DRIVES
}

\author{
METODA WYZNACZANIA I STANDARYZACJI \\ OSIĄGÓW SAMOLOTU Z NAPĘDEM ELEKTRYCZNYM \\ Zbigniew Jakielaszek, Mirosław Nowakowski \\ Instytut Techniczny Wojsk Lotniczych \\ e-mail: zbigniew.jakielaszek@itwl.pl; miroslaw.nowakowski@itwl.pl
}

\begin{abstract}
The study outlines the technique for flight tests carried out for a plane powered by an electric drive and the method for standardization of performance parameters applicable to evaluation of test results. Due to the relatively new type of drive, which is an electric motor, the literature references provide no descriptions of such issues. Therefore the solutions presented in the paper are the own contribution of the research team from Air Force Institute of Technology (ITWL).
\end{abstract}

Keywords: flight tests, standardization method

Streszczenie: $W$ pracy przedstawiono technike przeprowadzania prób $w$ locie $w$ odniesieniu do samolotów napędzanych silnikiem elektrycznym. Zaproponowano też metodę standaryzacji wyników badań. Ze względu na stosunkowo nowy rodzaj napędu - silnik elektryczny - brak jest w literaturze opisu podobnych zagadnień. Dlatego rozwiazania przedstawione $w$ pracy stanowiq autorska propozycje zespołu badawczego ITWL.

Stowa kluczowe: próby w locie, standaryzacja wyników badań 
A method for determination and standardization of performance parameters... Metoda wyznaczania i standaryzacji osiagów samolotu z napędem elektrycznym

\section{Introduction}

Each aircraft must undergo thorough and comprehensive inspections and tests with the aim to determine the flight performance of the aircraft and to check whether it can be operated with sufficient degree of safety. Such investigations always include flight tests that present one of key components and phases of such examinations and make it possible to compare actual flight performance of aircrafts against the requirements that underlay design and engineering efforts. Flight tests enable final evaluation of all outcomes from the extremely sophisticated process of aircraft engineering. They are also indispensable to determine the condition of the aircraft during its entire lifetime, since they provide widespread information about operability of its various units and subassemblies. In-flight examinations include test flights that can be carried out under various weather conditions, which is associated with momentary changes of weather during short-time periods, weather variability from one season of a year to another and operation of the aircrafts in various climatic zones where tests may be carried out. It is why there is a need to apply such research methods that enable uniformization of obtained test results and boil them down to conditions that are considered as the reference ones. Such conditions are detailed by the International Standard Atmosphere (ISA). At the same time, one has to take into account that results of various investigations may differ due to the fact that the actual weight of the aircraft may fluctuate from the rated weight assumed by the aircraft designer.

Standardization of examination results to the reference condition enables unbiased assessment whether or not the aircraft under test is in line with all the assumptions underlying its engineering. In the case of scheduled inspections and examinations after repairs or overhauls, flight tests make it possible to find out whether or not characteristic parameters of the aircraft have been altered and how much.

Results from flight tests reduced to reference conditions enable neutral comparison between different aircrafts. It is essential, for instance for tenders, when the utmost goal is to choose the best bid. In parallel, performance characteristics boiled down to reference conditions make it possible to find out which of the aircrafts subjected to the analysis meet the imposed requirements in the best way.

\section{Method for standardization of flight characteristics}

\section{Reference elevation}

Test flights assume keeping records on physical parameters of ambient air, i.e. its barometric pressure and temperature. In addition, it is sometimes reasonable to measure the geometrical elevation that is understood as the vertical distance from the earth surface. Pressure and temperature values may vary within a vast range depending on the season of year and current atmospheric conditions. Since flight characteristics of aircrafts do not directly depend on the geometrical elevation of the flight, it is not very important to measure just that parameter, while the impact of physical parameters of air is really essential. It is why the term of conventional 
reference elevation is defined and the parameters at that altitude correspond to International Standard Atmosphere (ISA). The values of flight parameters measured during test flights are recalculated with regard to that standardized reference elevation $H_{o d}$. It is assumed that the value of the specific flight parameters measured under actual conditions at the flight elevation $H_{r z}$ is constant and then such an elevation of $H_{o d}$ is sought so that the aircraft would achieve the same value of the measured parameter under ISA conditions. That $H_{o d}$ elevation is referred to as the reference (equivalent) elevation.

In practice, the reference elevation depends on the assumed criterion and may be defined in the following manner:

$H$ - geometrical elevation measured above the sea level or the level of the airfield;

$H_{\mathrm{p}}-$ barometric elevation determined according to the standard atmosphere ISA on the basis of already measured atmospheric pressure;

$H_{\rho}$ - elevation defined according to the air density and determined for the standard atmosphere on the basis of already measured air density,

$H_{\mathrm{T}}-$ elevation defined according to the air temperature and determined for the standard atmosphere on the basis of already measured air temperature.

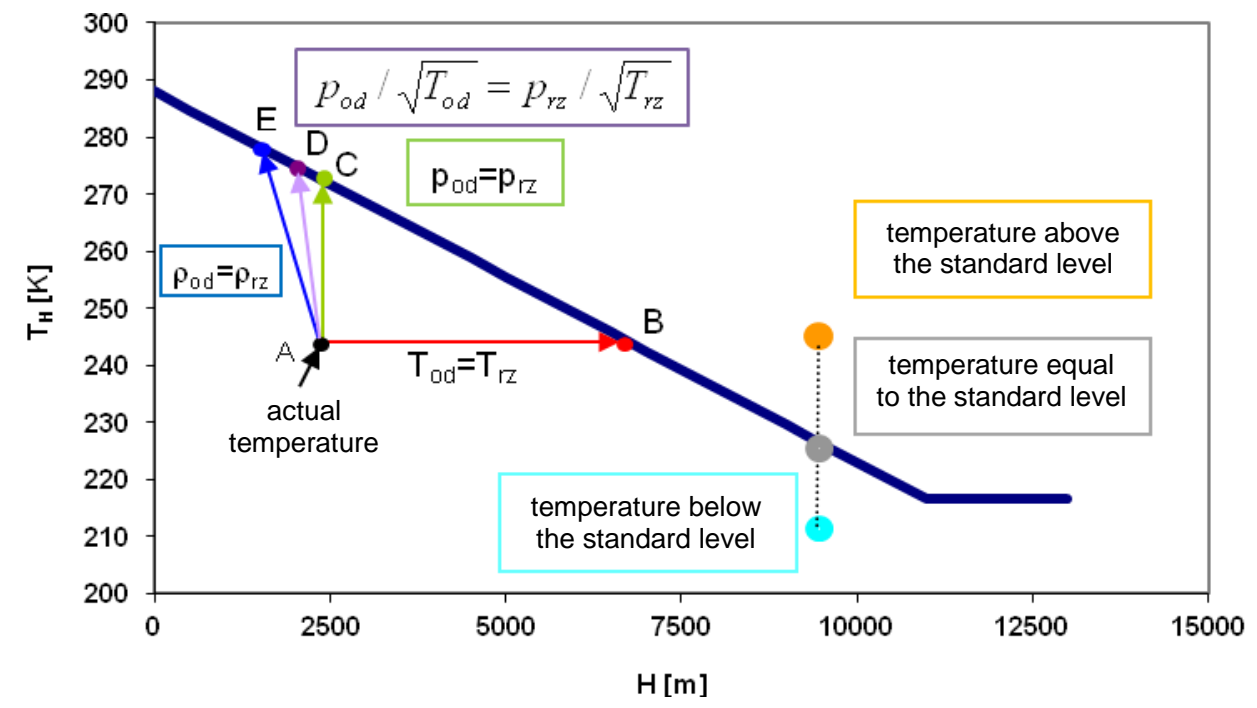

Fig. 1 Methods for selection of the reference elevation

For ISA, there is a direct and unambiguous interrelationship between the elevation, pressure and air temperature. For already known atmospheric pressure, it is easy to establish the barometric elevation $H_{p}$ and then other physical parameters of air, i.e. 
A method for determination and standardization of performance parameters... Metoda wyznaczania i standaryzacji osiagów samolotu z napędem elektrycznym

its temperature $T$ and density $\rho$. Nevertheless, values of these parameters measured during an aircraft flight most frequently deviate from the calculated references ones. It means that the actual temperature measured on flight is illustrated by a point located outside the $T_{H}=f(H)$ graph as shown in Fig. 1.

A similar effect will be spotted when the elevation $H_{T}$ is calculated on the basis of the measured temperature and then it is used to calculate the $p_{H}$ - the results of calculations will differ from the measured pressure.

The foregoing considerations demonstrate that definition of the reference elevation is ambiguous - a different value is obtained for elevation that is determined on the basis pressure measurements and a different one can be derived on the basis of the actual temperature of air. It is why a specific criterion has to be adopted, where the criterion is defined as the equivalence of a specific function of both pressure and temperature $f(p, T)$ under actual conditions of measurements on one side and the same function under reference conditions on the other side:

$$
f\left(p_{o d}, T_{o d}\right)=f\left(p_{r z}, T_{r z}\right)
$$

The " $o d$ " indexes stand for reference values corresponding to the International Standard Air (ISA), whilst " $r z$ " indexes refer to measurements under actual conditions.

- If $f(p, T)=T$, the equation (1) is reduced to $T_{o d}=T_{r z}$ and the reference altitude is deemed as the altitude determined according to temperature, i.e. $H_{o d}=$ $H_{T}$. Point A corresponds to point B on the characteristic curve for the reference atmosphere (Fig. 1).

- If $f(p, T)=p$, the equation (1) is reduced to $p_{o d}=p_{r z}$ and the reference altitude is deemed as the barometric altitude, i.e. $H_{o d}=H_{p}$. Point A corresponds to point $\mathrm{C}$ on the characteristic curve for the reference atmosphere (Fig. 1).

- If $f(p, T)=p / \sqrt{T}$ the equation (1) is transformed to $p_{o d} / \sqrt{T_{o d}}=p_{r z} / \sqrt{T_{r z}}$, and point $\mathrm{A}$ corresponds to point $\mathrm{D}$ on the characteristic curve for the reference atmosphere (Fig. 1).

If $f(p, T)=p / T$, the equation (1) is transformed to $p_{o d} / T_{o d}=p_{r z} / T_{r z}$ and the reference altitude is deemed as the elevation determined on the basis of air density, i.e. $H_{o d}=H_{\square}$, and point $\mathrm{A}$ corresponds to point $\mathrm{E}$ on the characteristic curve for the reference atmosphere (Fig. 1).

The method of differential corrections is derived from the assumption that flight characteristics of the aircraft (denoted with the letter ' $X$ ') depend on both atmospheric conditions (e.g. temperature $T$ and pressure $p$ ), the driving unit of the machine (e.g. $\operatorname{rpm} n$ ) and the own parameters of the aircraft (e.g. its own weight $m$ ).

$$
X=f(p, T, n, m)
$$


If any of the foregoing parameters is altered, it entails changes in flight characteristic. The differential can be expressed by means of the following equation:

$$
d X=\sum_{i} \frac{\partial X}{\partial W_{i}} d W_{i}=\sum_{i} \frac{X}{W_{i}}\left(\frac{W_{i}}{X} \frac{\partial X}{\partial W_{i}}\right) d W_{i}=X \sum_{i} X_{W_{i}} \frac{d W_{i}}{W_{i}}
$$

where $W_{i}$ stands for parameters which affect the specific characteristic and $X_{W_{i}}$ are non-dimensional factors which define how much the $X$ characteristic is deviated when the $W_{i}$ parameter is altered by $1 \%$.

$$
X_{W_{i}}=\frac{W_{i}}{X} \frac{\partial X}{\partial W_{i}}=\frac{\partial X / X}{\partial W_{i} / W_{i}}
$$

These factors depend on design and aerodynamic properties of the aircraft under tests, properties of its driving unit as well as on the air pressure $p$ and temperature $T$. Frequently, the relationship (2) is expressed in the form of the following power function:

$$
X=\prod_{i} W_{1}^{k_{1}} W_{2}^{k_{2}} \cdot . . \cdot W_{i}^{k_{i}} \cdot . . \cdot W_{K}^{k_{K}}
$$

Logarithmic transformation for both sides of the foregoing equation leads to:

$$
\ln X=\sum_{i} k_{i} \ln W_{i}
$$

Further differentiation of the above provides:

$$
\frac{d X}{X}=\sum_{i} k_{i} \frac{d W_{i}}{W_{i}}
$$

And then:

$$
d X=\sum_{i} \frac{X}{W_{i}} k_{i} d W_{i}
$$

Comparison of the expressions (3) and (8) makes it possible to note that for that specific case the $X_{W_{i}}$ factors are equal to exponents of power monomials that are used in (5).

$$
X_{W_{i}}=k_{i}
$$

The most substantial impact on variations of flight characteristics falls to air pressure and temperature. 
A method for determination and standardization of performance parameters... Metoda wyznaczania i standaryzacji osiagów samolotu z napędem elektrycznym

It means that the factors $X_{p}$ and $X_{T}$ are of the highest importance.

$$
\left.X_{p}=X_{p}(\text { aircraft properties, } p, T), X_{T}=X_{T} \text { (aircraft properties, } p, T\right)
$$

These factors can be obtained from calculations, which is not always possible, or from dedicated test flights completed for the specific aircraft type. Frequently, standard arrays of such factors are developed only for generally available typical aircrafts due to high expenses necessary to develop these arrays. The deviations of actual temperature from ISA conditions are usually less or equal $7 \%$ whilst pressure deviations remain within $20 \%$. If so, the $X_{p}$ and $X_{T}$ can be considered as fixed values which depend merely on other invariable properties of the aircraft.

$$
X_{p}=\text { const }, \quad X_{T}=\text { const }
$$

Hence, the differentials in the equation (3) can be substituted with increments:

$$
d X=\Delta X=X_{o d}-X_{r z}, d p=\Delta p=p_{o d}-p_{r z}, d T=\Delta T=T_{o d}-T_{r z}
$$

Finally, the following formula is obtained, which enables calculation of increments and actual value for each specific flight parameter under reference conditions.

$$
\begin{gathered}
\frac{\Delta X}{X_{r z}}=\left(X_{p} \frac{\Delta p}{p_{r z}}+X_{T} \frac{\Delta T}{T_{r z}}\right) \\
X_{o d}=\frac{X_{r z}}{1-\left[X_{p}\left(1-\frac{p_{r z}}{p_{o d}}\right)+X_{T}\left(1-\frac{T_{r z}}{T_{o d}}\right)\right]}
\end{gathered}
$$

\section{Theoretical background for in-flight investigation of electric motors}

The available literature references provide no information related to the impact of ambient conditions on the operation of electric motors used as driving units of aircrafts. It was the reason that triggered research studies on possible relationships between ambient parameters and power developed by electric motors. The studies were carried out for the brushless DC electric motor of the AXI 2820/14 type and power of 360W. An appropriate test-bench was built, as shown in Fig. 2. The motor was supplied with direct current with measurements of the voltage $U$ and current $I$ in the power supply line. It enabled calculation of power supplied to the motor.

$$
N_{d}=U \cdot I
$$

The motor was connected to the load via a coupling. The studies included measurements of the motor torque $M$ and its rotation speed $\omega[\mathrm{rad} / \mathrm{s}]$, which made it possible to calculate the efficient (power) output of the motor:

$$
N_{e}=M \cdot \omega
$$


and its efficiency:

$$
\eta=\frac{N_{e}}{N_{d}}=\frac{M \cdot \omega}{U \cdot I}
$$

The motor under test was placed inside a climatic chamber and the temperature and pressure in the chamber were cycled according to the prescribed schedule in order to find the impact of such variations on the operational parameters of that motor. The measurements have revealed that pressure variations have no impact on the motor power and efficiency. Thus, all further measurements related to the impact of the ambient temperature. Figures 3-5 show diagrams for measured parameters as functions of time. The full measurement cycle lasted about 170 minutes and the ambient temperature was cycled from $230 \mathrm{~K}$ to $328 \mathrm{~K}\left(-43^{\circ} \mathrm{C}\right.$ to $\left.55^{\circ} \mathrm{C}\right)$. Fig. 3 shows that the motor temperature exceeded the ambient temperature during the entire measurement cycle with the temperature offset of about $14 \mathrm{~K}$, which is the effect of thermal energy dissipation by the motor itself. It is confirmed by Fig. 4 with the diagram for variation of supplied power $N_{d}$ that still exceeds the power output $N_{e}$ developed by the motor. One can also note that any temperature decrease leads to increase of supplied power with simultaneous drop of the efficient power. It leads to deterioration of the motor efficiency in pace with the temperature decrease, which is shown in Fig. 5.

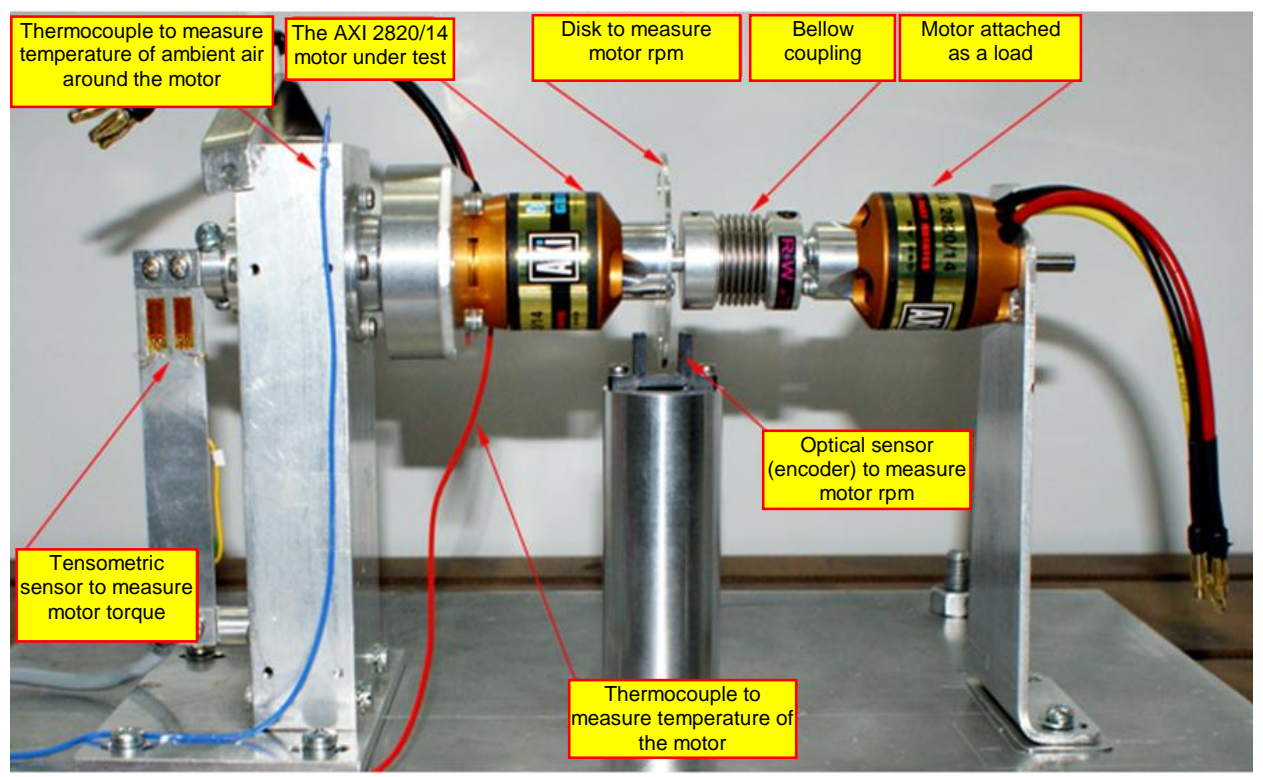

Fig. 2 Test bench to investigate characteristic parameters of the AXI 2820/14 electric motor 
A method for determination and standardization of performance parameters... Metoda wyznaczania i standaryzacji osiagów samolotu z napędem elektrycznym

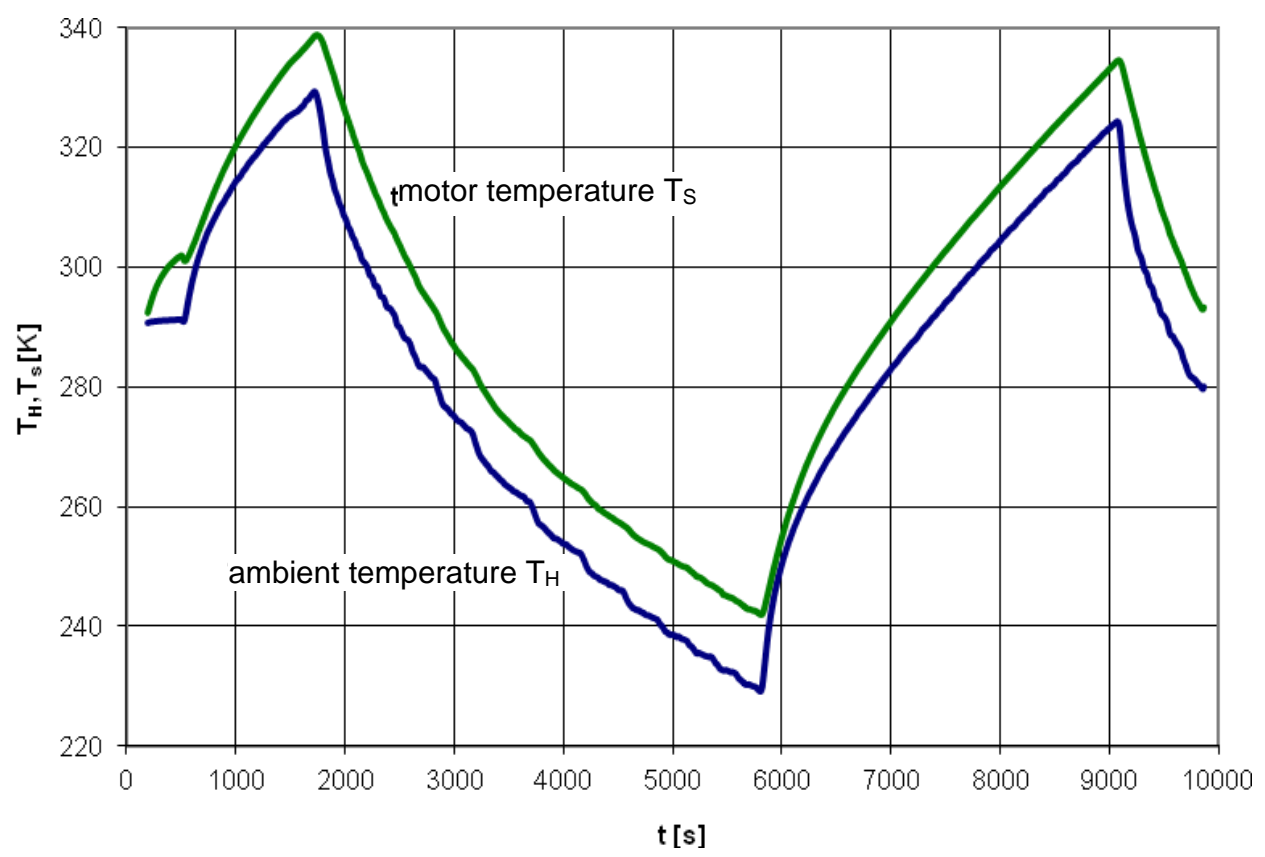

Fig. 3 Variations of the ambient temperature $T_{H}(t)$ and temperature of the electric motor $T_{s}(t)$

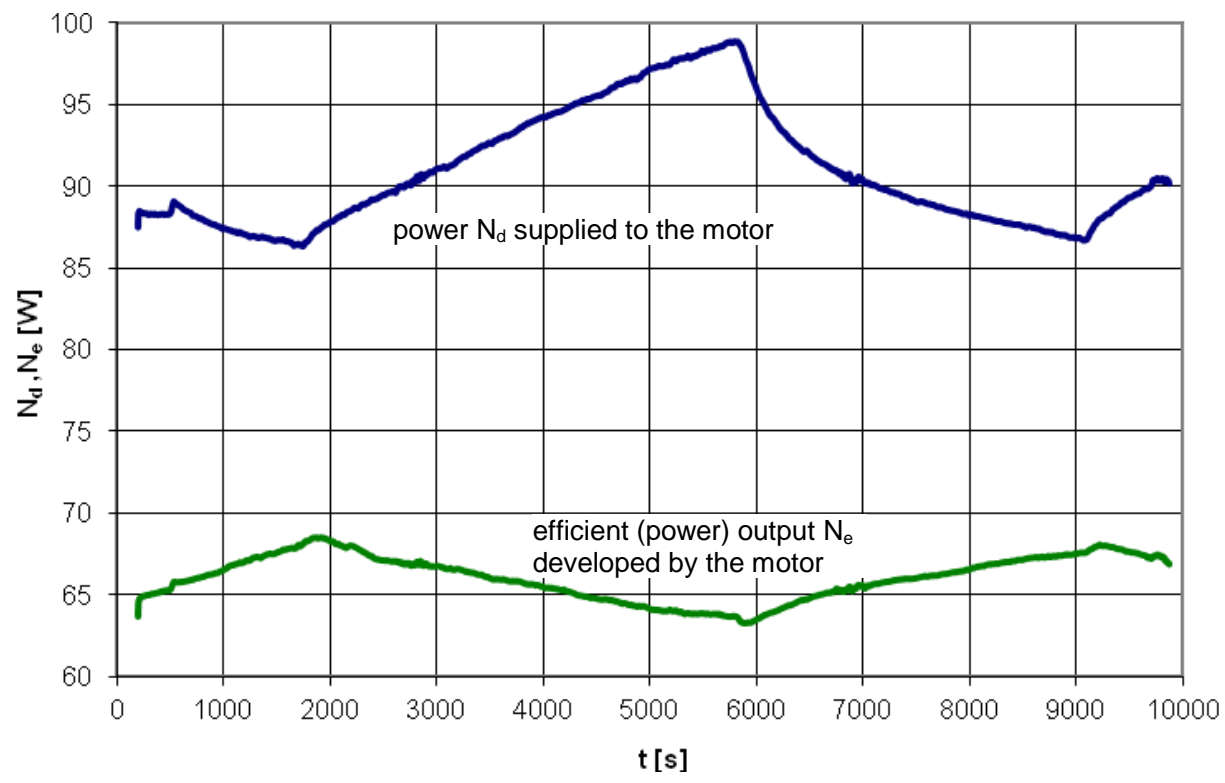

Fig. 4. Variations of the power $N_{d}(t)$ supplied to the motor and its efficient (power) output $N_{e}(t)$. 


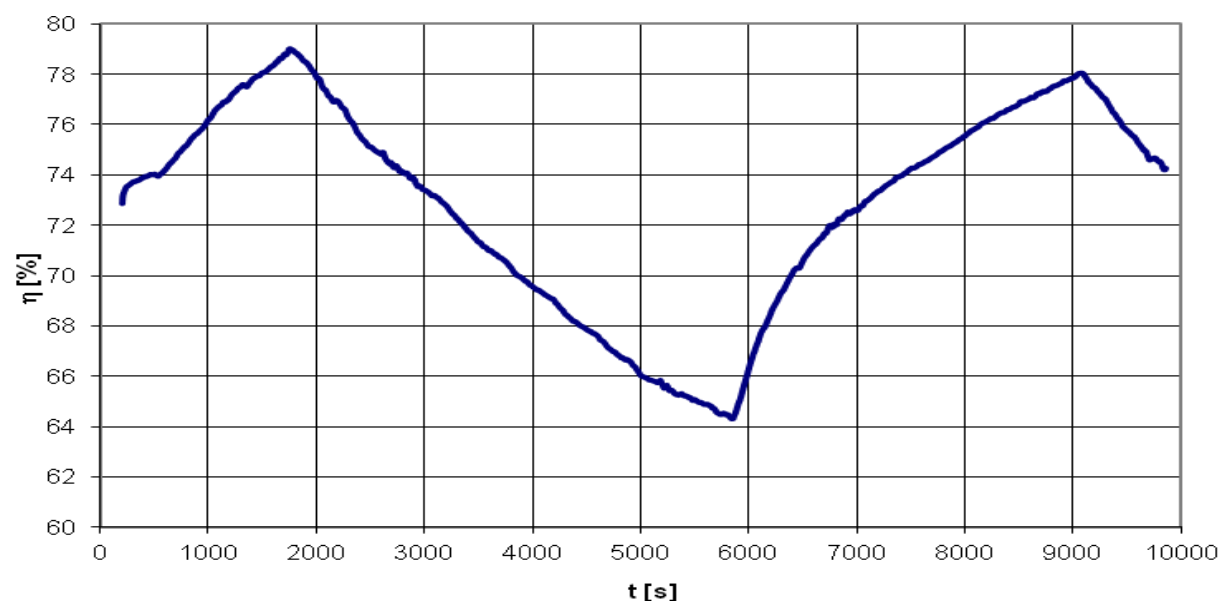

Fig. 5 Variations of the electric motor efficiency $\eta(t)$

Since variations of all operational parameters measured during investigation of the electric motor were entailed by the ambient temperature, it was reasonable to plot graphs that depict interrelationships between the motor temperature, the supplied power and the power output, respectively $N_{d}$ and $N_{e}$, as well as between the efficiency $\eta$ and the $T_{H}$ temperature. These plots are shown in Fig. 6 to Fig. 8. Fig. 6 confirms an unambiguous relationship between the $T_{s}$ and $T_{H}$ temperatures with a hysteresis of the plot. In Fig. 6 and Fig. 7 an approximating line was plotted for the results obtained from measurements. These data make it possible to establish how the motor efficiency $\eta$ depends on the ambient temperature $T_{H}$ (Fig. 8) in order to establish the interrelationships between these parameters and the ambient temperature $T_{H}$.

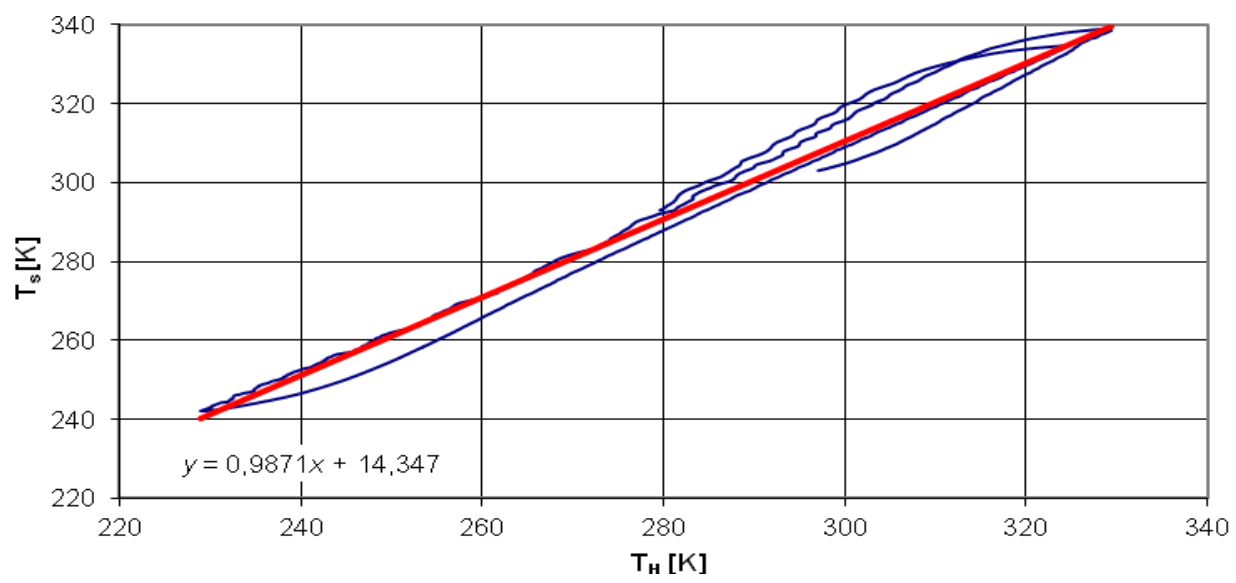

Fig. 6 Relationship between the electric motor temperature $T_{S}$ and the ambient temperature $T_{H}$ 
A method for determination and standardization of performance parameters... Metoda wyznaczania i standaryzacji osiagów samolotu z napędem elektrycznym

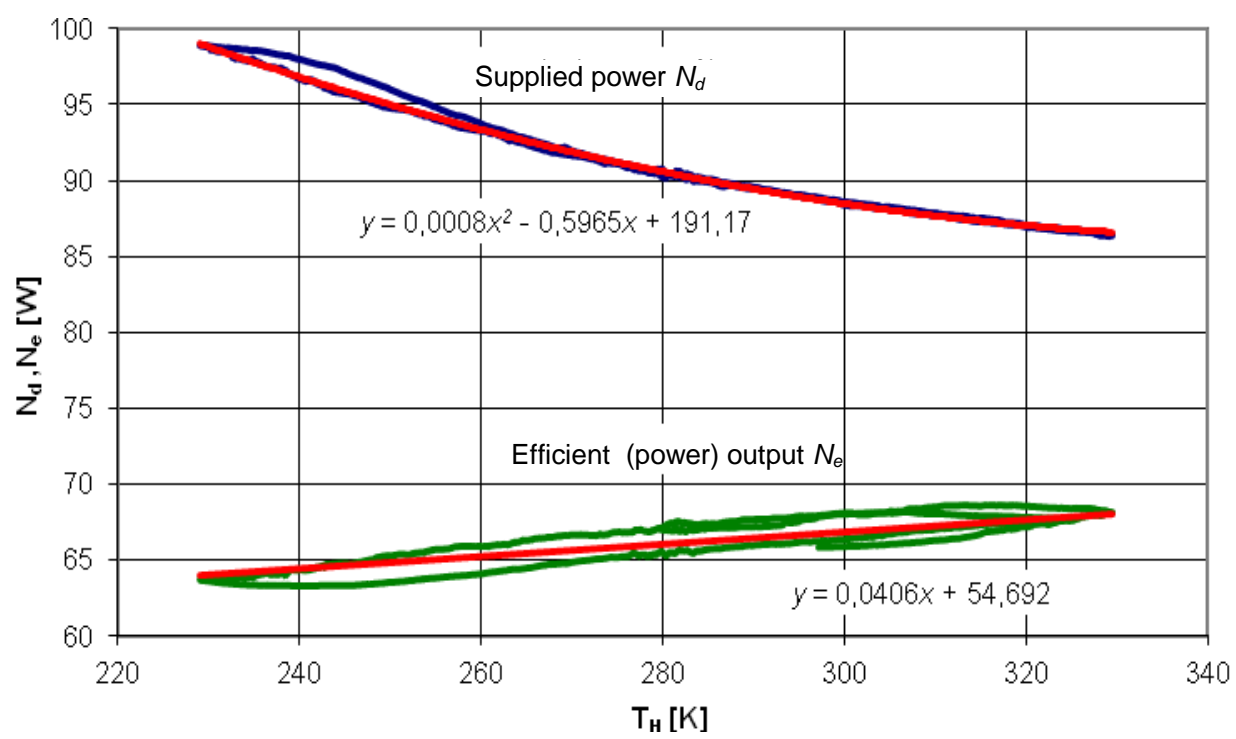

Fig. 7 The supplied power $N_{d}$ and efficient (power) output $N_{e}$ of the electric motor as functions of the ambient temperature $T_{H}$.

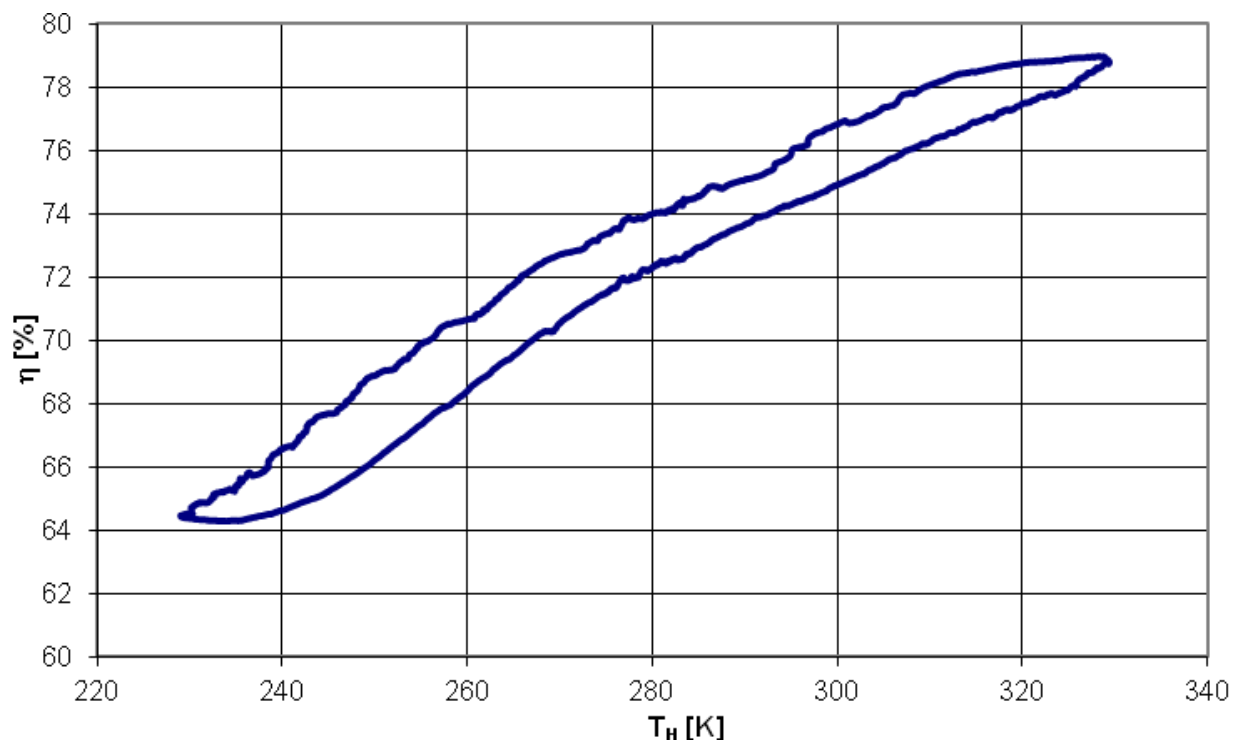

Fig. 8 The relationship between the electric motor efficiency $\eta$ and its ambient temperature $T_{H}$ 


\section{Standardization of the maximum speed and ascending velocity for aircrafts with electric drives}

To establish methods for standardization of characteristic velocities, the assumption has been made that the aircraft is provided with an electric motor designed to drive an airscrew with a constant pitch. Power delivered to the aircrew may be changed by variations of the motor rpm. The calculations benefit from the method of differential corrections and the barometric elevation is adopted as the reference elevation.

The conditions which describe horizontal flights of aircrafts are defined firstly by a balance between the aerodynamic lift and the gravitation force, and secondarily by the balance between the power of the motor and airscrew arrangement and the power developed by forces of aerodynamic resistance. These two relationships can be expressed by the following formulas:

$$
\begin{gathered}
\eta_{s m} N_{e}=C_{x a} \frac{\rho_{H} V^{3}}{2} S \\
m g=C_{z a} \frac{\rho_{H} V^{2}}{2} S
\end{gathered}
$$

On the basis of similarity conditions for flight, the following equation can be formulated as a relative differential for characteristic velocities.

$$
\frac{d V}{V}=V_{T} \frac{d T_{H}}{T_{H}}+V_{p} \frac{d p_{H}}{p_{H}}+V_{n} \frac{d n}{n}+V_{m} \frac{d m}{m}
$$

The foregoing assumption that the barometric elevation is used as the reference means that $d p_{H}=0$, which simplifies the previous equation:

$$
\frac{d V}{V}=V_{T} \frac{d T_{H}}{T_{H}}+V_{n} \frac{d n}{n}+V_{m} \frac{d m}{m}
$$

The multiplication factors equal, respectively, the following [2]:

$$
V_{T}=\frac{2 \eta_{C_{N}}-\frac{\eta_{M_{k}}}{2}+1.76 g_{R e}-g_{C_{z a}}+\frac{g_{M}}{2}+\frac{5}{2}}{3-2 g_{C_{z a}}+g_{R e}+g_{M}-\eta_{J}-\eta_{M_{k}} \frac{V^{2}}{V^{2}+V_{o b w}^{2}}}
$$


A method for determination and standardization of performance parameters...

$$
\begin{gathered}
V_{p}=\frac{-\eta_{C_{N}}-g_{R e}+g_{C_{z a}}-1}{3-2 g_{C_{z a}}+g_{R e}+g_{M}-\eta_{J}-\eta_{M_{k}} \frac{V^{2}}{V^{2}+V_{o b w}^{2}}} \\
V_{n}=\frac{\eta_{M_{k} \frac{V^{2}}{V^{2}+V_{o b w}^{2}}-\eta_{J}-3 \eta_{C_{N}}}^{3-2 g_{C_{z a}}+g_{R e}+g_{M}-\eta_{J}-\eta_{M_{k}} \frac{V^{2}}{V^{2}+V_{o b w}^{2}}}}{V_{m}=\frac{-g_{C_{z a}}}{3-2 g_{C_{z a}}+g_{R e}+g_{M}-\eta_{J}-\eta_{M_{k}} \frac{V^{2}}{V^{2}+V_{o b w}^{2}}}}
\end{gathered}
$$

The foregoing equations can be simplified under the following postulations:

- factors are zeroed for flights with the maximum speed efficiency:

$$
\eta_{J}=0, \eta_{C_{N}}=0
$$

- impact of the Reynolds number on air resistance to the aircraft is negligible:

$$
g_{R e}=0
$$

- impact of the Mach number (which expresses the speed of the airscrew tips) on the efficiency factor of the airscrew $\eta_{s m}$ is negligible:

$$
\eta_{M_{k}}=0
$$

- impact of the air compressibility on the aerodynamic properties of the aircraft is negligible (insignificant)

$$
g_{M} \approx 0, \quad g_{C_{z a}}=g_{C_{z a_{-}} i}\left(g_{C_{z a_{-}} f} \approx 0\right)
$$

Thus, the foregoing equations are reduced to the following:

$$
V_{T}=\frac{\frac{5}{2}-g_{C_{z a_{-} i}}}{3-2 g_{C_{z a_{-} i}}}
$$




$$
\begin{gathered}
V_{p}=\frac{C_{z a_{-} i}-1}{3-2 g_{C_{z a_{-} i}}} \\
V_{n}=0 \\
V_{m}=\frac{-C_{z a_{-} i}}{3-2 g_{C_{z a_{-} i}}}
\end{gathered}
$$

where:

$$
g_{C_{z a-} i}=\frac{2}{\frac{\pi \lambda_{e f} C_{x a 0}}{C_{z a}^{2}}+1}
$$

With the assumption that the barometric elevation is adopted as the reference one, i.e. $d p_{H}=0$, the following is obtained: [2]:

- relative differential for the maximum speed:

$$
\frac{d V_{\max }}{V_{\max }}=V_{T} \frac{d T_{H}}{T_{H}}+V_{n} \frac{d n}{n}+V_{m} \frac{d m}{m}
$$

- relative differential for the induced maximum speed:

$$
\frac{d V_{i_{-} \max }}{V_{i_{-} \max }}=\left(V_{T}-\frac{1}{2}\right) \frac{d T_{H}}{T_{H}}+V_{n} \frac{d n}{n}+V_{m} \frac{d m}{m}
$$

- relative differential for the ascending velocity:

$$
\frac{d W_{g}}{W_{g}}=A_{W_{g}} \frac{d T_{H}}{T_{H}}
$$

where:

$$
A_{W_{g}}=\frac{1}{2} \frac{V_{i}}{W_{g} K \sqrt{\frac{T_{0}}{p_{0}}} \sqrt{\frac{p_{H}}{T_{H}}}},
$$

The relative differential $\frac{d W_{g}}{W_{g}}$ depends solely on the induced speed, aerodynamic excellence of the aircraft and airscrew characteristic parameters. 
A method for determination and standardization of performance parameters... Metoda wyznaczania i standaryzacji osiagów samolotu z napędem elektrycznym

\section{Flight ranges and durations of aircrafts with electric motors}

Aircrafts with electric drives are supplied from rechargeable batteries. Capacity of such a battery substantially depends on the ambient temperature, which is illustrated in Fig. 9. The graph illustrates that temperature decrease leads to reduction of the battery capacity and, consequently, adversely affects the flight ranges and duration. Simultaneously, the motor efficiency is worsened, which means that at lower temperatures the motor must receive more power from the batteries to maintain the same power output. In consequence, the flight ranges and durations are reduced even more.

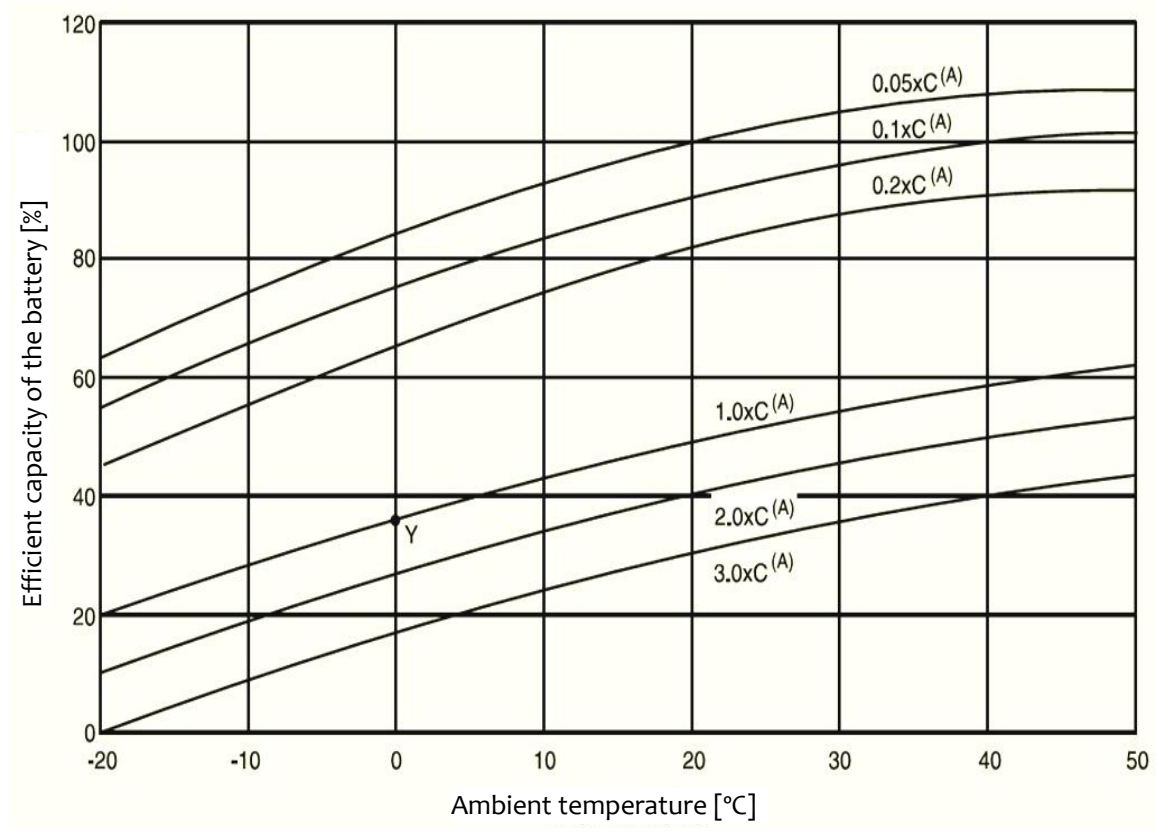

Fig. 9 Capacity of rechargeable batteries as a function of temperature [1]

Similarly to internal combustion engines, the following terms can be defined [2]:

Hourly consumption of charge $\boldsymbol{I}_{h}$ - amount of electric charge that is consumed by the aircraft drive during one hour of a flight:

$$
I_{h}=\frac{Q}{t} \quad\left[\frac{\mathrm{C}}{\mathrm{h}}\right]
$$

Kilometric consumption of charge $\boldsymbol{I}_{\boldsymbol{k}}$ - amount of electric charge that is consumed by the aircraft drive per one kilometer of flight:

$$
I_{k}=\frac{Q}{L} \quad\left[\frac{\mathrm{C}}{\mathrm{km}}\right]
$$


Consumption of charge per power unit $\boldsymbol{i}_{j}$ - amount of electric charge that is consumed by the aircraft drive during one hour to develop a unit of output power:

$$
i_{j}=\frac{I_{h}}{N_{e}} \quad\left[\frac{\mathrm{C}}{\mathrm{W} \cdot \mathrm{h}}\right]
$$

The following relationship exists between hourly and kilometric consumption of electric charge:

$$
I_{k}=\frac{Q}{L}=\frac{Q}{V \cdot t}=\frac{I_{h}}{3,6 \cdot V} \quad\left[\frac{\mathrm{kg}}{\mathrm{km}}\right]
$$

where the multiplication factor applies when the aircraft speed is expressed in $[\mathrm{m} / \mathrm{s}]$. It is omitted for speed denominated in $[\mathrm{km} / \mathrm{h}]$.

The maximum flight reach can be achieved when the kilometric consumption of electric charge is reduced to the minimum. For horizontal flights, the kilometric consumption of electric charge can be expressed as a function of consumption of the electric charge per power unit and characteristic parameters of the aircraft and its airscrew.

Upon substitution of (35) into (38), the following formula is obtained:

$$
I_{k}=\frac{I_{h}}{3,6 \cdot V}=\frac{i_{j} N_{e}}{3,6 \cdot V}
$$

With consideration to the equation of the aircraft motion with the power balance of the driving system and the power necessary to overcome the air resistance $\eta_{s m} \cdot N_{e}=C_{x a} \frac{\rho_{H} V^{3}}{2} S=P_{x a} V$ the expression for kilometric consumption of electric charge adopts the following form:

$$
I_{k}=\frac{i_{j} N_{e}}{3,6 \cdot V}=\frac{P_{x a} \cdot i_{j}}{3,6 \eta_{s m}}=\frac{m g}{3,6} \frac{i_{j}}{\eta_{s m} K}
$$

The equation shows that the maximum reach of aircrafts with electric drives shall be achieved for the maximum of the aerodynamic excellence $K$.

\section{Conclusions}

The study reveals the investigation method applicable to aircrafts with electric drives. This method enables an unbiased and objective interpretation of test results through their appropriate standardization in which the differences between actual atmospheric conditions and the conditions stipulated by the International Standardized Atmosphere (ISA) are taken into account. These differences directly 
A method for determination and standardization of performance parameters... Metoda wyznaczania i standaryzacji osiagów samolotu z napędem elektrycznym

affect both characteristic parameters of the driving system (a motor and an airscrew as an option) and aerodynamic forces which act on the aircraft.

The study is focused on measurements of key performance parameters, i.e. characteristic velocities and consumption of electricity that is decisive for both flight reach and duration.

\section{References}

[1] Akumulatory, Elektronika dla wszystkich nr 10/96, 11/96. [Rechargeable batteries. Electronics for everyone. Vol. 10/96, 11/96].

[2] Nowakowski M.: Metody badań w locie osiagów samolotów z różnymi rodzajami napędów. Wydawnictwo ITWL. Warszawa 2013. ISBN 978-8361021-92-6. [Methods of in-flight tests for performance parameters of aircrafts with various driving systems. ITWL Publishing House, Warsaw 2013, ISBN 978-83-61021-92-6].

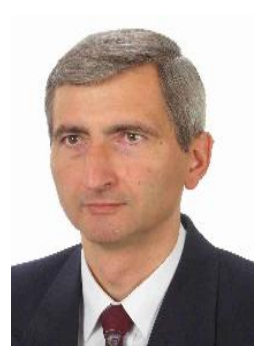

Mirostaw Nowakowski, DSc., Eng. has been heading the Division of Airplanes and Helicopters at Air Force Institute of Technology (ITWL) since 1998. He is involved in research and development projects in the field of aviation technology ordered by Polish Air Forces and Polish industrial enterprises. His research studies are focused on certification tests (upon government order) carried out for the following airplanes: PZL130 Orlik, M-28 Bryza, TS-11 Iskra, MiG-29, Su-22 and helicopters: W-3 Sokót, SW-4, Mi-8, Mi-14, Mi-17, Mi-24. He participated in the development of models for dynamic behaviour of aircrafts in flight related to such aircrafts as: TS-11 Iskra, MiG-29, Su-22 and PZL-130 Orlik, together with their verification, as well as Unmanned Aerial Vehicles, i.e. controllable air targets. The team headed by Dr Nowakowski has launched more than 200 systems of S2-3a type which are unique within the country and designed to keep records and decode flight parameters of aircrafts in service both domestically and abroad.

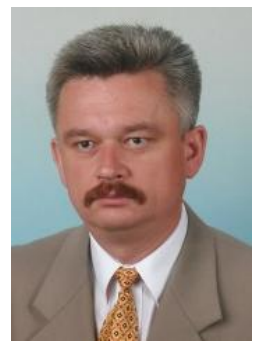

Zbigniew Jakielaszek, MSc., Eng. graduated Military University of Technology in 1987 and majored in on-board equipment of airplanes and helicopters. Currently he is employed at the Air Force Institute of Technology (ITWL) as a leader of a workshop and a research team which deals with measurement instruments for inflight tests of aircrafts. Along with his team, he developed measurement and data recording systems designed to examine such airplanes as MiG-29, MiG-29UB, Su-22, Su-22 UM3K, TS-11 Iskra, PZL-130 TC-I i TC-II Orlik, as well as helicopters: Mi-14, Mi-17, Mi-24D and SH-2G Kaman. 